\title{
AEROMAGNETIC STRIP MAP ACROSS THE CENTRAL SIERRA NEVADA, CALIFORNIA
}

\author{
GEOPHYSICAL INVESTIGATIONS \\ MAP GP-657
}

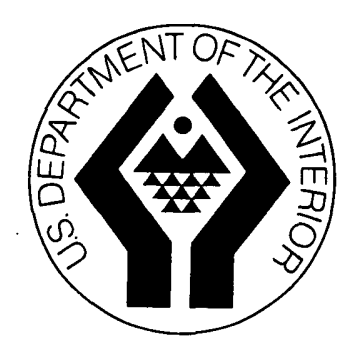

PUBLISHED BY THE U. S. GEOLOGICAL SURVEY WASHINGTON, D.C. 